\title{
Getting learners to speak in the (Indonesian) ELT Classroom
}

\author{
Ivor Timmis \\ Department of Languages, Leeds Beckett University - UK \\ I.Timmis@leedsbeckett.ac.uk
}

\begin{abstract}
Despite realising the importance of acquiring good speaking skill, English teachers in Indonesia find that it is challenging to get their learners to speak during classes. Potential reasons for reticence are: their lack of vocabulary, dependency of L1 translation, and tendency to give short answers. Therefore, it is crucial to provide the teachers with practical techniques that they can use in their daily teaching to address this reticence. By providing scaffolding to the speaking activities, which includes how to structure the speaking activities and prepare the learners before the activities, the teacher can make speaking tasks more productive for learners. Moreover, the amount of scaffolding can be adjusted to suit the characteristics and needs of the learners to create better and lasting impact.
\end{abstract}

Keywords: Speaking, reticence, scaffolding, Indonesian ELT classroom.

DOI: http://dx.doi.org/10.26418/jeltim.v1i1.31223

\section{INTRODUCTION}

The status of speaking skills in ELT is rather unclear. While speaking is often a highly prized skill, as it supports international communication and is valuable for employment purposes, it is sometimes avoided by both teachers and learners in the classroom. Though they may recognise the need to develop speaking skills, teachers may not be sure about how to do it. As Goh (2017: 256) puts it: 'It seems clear to me that some teachers still lack confidence when it comes to planning and conducting speaking and listening lessons'. A further complicating factor is that speaking is a skill which is often not assessed in national examinations since it is both time-consuming and expensive skill to do so. It is also true that writing has traditionally been seen as a higher status skill than speaking in some contexts. This view is summarised by Goh (2017: 256) thus: 'Speaking is often seen as less important compared with reading and writing because of public examinations which are still weighted more heavily towards reading and writing'. In this article, I would like to discuss some of the specific factors which make speaking in another language challenging: we need to understand the problem before we decide how to address it. I would then like to outline some practical ways in which we might address the challenge presented by getting learners to speak English in the ELT classroom.

\section{THE NATURE OF SPEAKING SKILL}

Before we consider what is involved in the speaking skill, it is important to establish what speaking is not: learners doing repetition drills or reproducing memorised dialogues are not speaking
English; they are simply making English noises. There is a great difference between activities which simply constitute oral practice of grammar and genuine speaking activities. Real speaking activities involve learners making choices, at some level, over both form and content, and generally involve a degree of spontaneity. In other words, such activities require learners to make choices about what to say and how to say it. Sooner or later, learners need to be able to do this quite quickly. It is these requirements that make speaking challenging both cognitively and affectively. The cognitive challenge is neatly summarised by Burns and Hill (2013: 232):

Speaking is a complex mental process combining various cognitive skills, virtually simultaneously, and drawing on working memory of words and concepts, while self-monitoring.

What we have to do when we speak, then, is decide on the message we want to communicate and select words and structures which will deliver the message. At the same time, we need to keep in mind that the words and structures selected to communicate the basic message must also be socially appropriate for the context. And while all this is going on, we need to monitor whether we are delivering the message in the way we intended to and whether the message is being received in the way we intended. This is a real achievement, especially in a second language!

We also need to consider the affective challenge i.e. what is involved at an emotional level. As Hughes (2010: 207) points out, 'speaking is closely linked to identity, emotional states and affective factors'. As soon as we speak, we reveal something 
of our identity. Among the aspects of our identity which can be revealed when you speak are: the region you are from, your social class, your educational level and your personality. When you speak, you may also reveal your emotional state at that moment e.g. whether you are feeling confident, calm, nervous or upset. In addition to these factors, we need to take into account context and situation. In terms of the level of affective challenge, for example, speaking to an old friend in a café is far different from making a speech in front of an audience of 500. It is perhaps the affective challenge in particular which can make learners reticent or anxious in class. They may fear that, as they struggle to communicate in English they are projecting a diminished identity, leaving them vulnerable to mockery and loss of self-esteem. This may be particularly true of teenagers, who are still in the process of establishing their identity.

Anecdotal evidence from discussions with Indonesian colleagues suggests that reticence is quite a widespread problem in the Indonesian ELT classroom. A particular Indonesian colleague was kind enough to share with me his perception of the problems with getting learners to speak in the Indonesian classroom. The first problem he identified was the general classroom culture in Indonesia where learners are perhaps not used to making an active contribution in the classroom in English or, indeed, in any other subject. This problem, in my experience, is certainly not confined to Indonesia, and applies to a number of other countries (I currently have a $\mathrm{PhD}$ student, for example, studying reticence among Spanish undergraduates studying English). The second problem he identified was a lack of vocabulary needed to carry out the activity, identifying the repeated use of a very narrow range of vocabulary as a particular difficulty. He also noted over-use of translation from L1 as a hindrance to fluency. The final problem my Indonesian colleague referred to was a tendency to give very short answers, without providing the elaboration which is required, for example, in IELTS examinations. Again, he noted that this tendency to provide minimal responses is not restricted to the ELT classroom in Indonesian education.

\section{ADDRESSING THE PROBLEM OF RETICENCE}

While we need to be fully aware of the nature and scale of the challenge in getting learners to speak in the ELT classroom, we must not despair! It is my conviction, supported to some extent by experience, that many, though admittedly not all, learners actually want to talk if they are given the tools to do so. These tools, I argue, can be supplied in the form of appropriate 'scaffolding' of activities: 'scaffolding' refers to the support we give to learners to carry out a speaking activity which they might struggle with independently (Goh 2017). To be more specific, this scaffolding, I aim to show, involves the way we prepare learners before the activity, and the way we structure activities, so that learners have the language and guidance necessary to perform the activity. It is important to note that the amount of scaffolding can be adjusted according to the learners' abilities and confidence. Below I show practical examples of how such scaffolding can be constructed at different levels (high, medium and low), explaining the rationale for the way the specific activities are scaffolded. The over-riding principle for all these activities is that they try to exploit some kind of communication gap i.e. the fact that learners have different knowledge, experience and opinions and, therefore, a real reason to communicate with each other. Two other features of these activities are that, where possible, they offer scope for personalisation, and they begin with concrete issues before moving to more abstract topics.

It is important to point out that the principles discussed below can be applied both to the design and to the adaptation of activities. Teachers may not have the time or opportunity to design their own activities from zero, but by making quite small adjustments to the coursebook materials they have, they can still make speaking activities work more productive than they otherwise might be. I have included examples in the appendix of activities from an Indonesian coursebook which I adapted with the aim of making them more effective. The adapted activities were trialled in the classroom by an Indonesian colleague who reported that the changes made a positive difference. I adapted a number of activities in this way and, on reviewing the adapted versions, found some common features. The common features involved introducing and practising a limited amount of key vocabulary, with a focus on both meaning and pronunciation; structuring the interaction so it is clear when a particular learner is expected to speak; introducing a role for the teacher in previewing and/or concluding the activity. I have included some examples in the appendix; for further examples of how speaking activities can be adapted, see Timmis (2016).

\section{SUPPORTED SPEAKING ACTIVITIES \\ 4.1 High Scaffolding Activities}

The design principles behind high scaffolding activities are that they provide most of the language and content required for the activity, as well as providing a tight structure in terms of speaking turns. In other words, learners are closely guided as to when to speak and what to say. In such activities, learners may, for example, simply be asked to adapt 
or reconstruct the dialogue in the coursebook or a dialogue the teacher has written. If more confident learners want to go further than what is provided, then that, of course, is a good thing!

1a) An open and shut case

- Learners repeat the given dialogue as a whole class.

- Learners repeat the dialogue in pairs or threes (depending on the number of characters in the dialogue), with each learner taking a role.

- Learners change roles and repeat the dialogue again.

- Learner A keeps his book open, but Learner B closes his book. They repeat the dialogue with Learner B working from memory.

- Learner B keeps his book open, but Learner A closes his book. They repeat the dialogue with Learner a working from memory.

- Both learners close their books and repeat the dialogue from memory.

- All learners close their books and help the teacher to reconstruct the dialogue on the board from memory.

1b) Disappearing dialogue

- The teacher writes the coursebook dialogue on the board.

- Learners repeat the dialogues as a whole class.

- Learners repeat the dialogue in pairs or threes (depending on the number of characters in the dialogue), with each learner taking a role.

- The teacher rubs out some words of the dialogue. Learners repeat the dialogue, working partly from memory.

- The teacher rubs out some more words from the dialogue. Learners repeat the dialogue working mostly from memory.

- The teacher rubs out all the words of the dialogue. Learners repeat the dialogue working completely from memory.

- The learners help the teacher to rewrite the dialogue on the board.

1c) personalise the dialogue

Example dialogue

Wisma: What is your favourite subject, Ilham?

Ilham: Mathematics. What about you, Wisma?

Wisma: Why is that?

Ilham: I like solving problems. What is your favourite subject?

Wisma: History.

Ilham: Why is that?

Wisma: I like stories from the past.

Ilham: Me too.

- Learners practise the dialogue as a whole class.

- Learners practise the dialogue in pairs.

- Learners change roles and practise again.
- Partner A continues as the interviewer, but partner B gives his or her own answers to the questions (true or invented).

- Partner B continues as the interviewer, but partner A gives his or her own answers (true or invented).

\subsection{Medium Scaffolding Activities}

The main principles behind medium scaffolding activities are that some, but not all, of the language and content required for the activity is supplied for the learners. The interaction is also highly structured. However, what is given to the learners is only intended to be a starting point, a kind of springboard to stimulate further discussion.

2a) Skeleton Sentences

1. Complete the sentences so that they are true for you.

2. Work with a partner and talk about your interests.

(a) I've never tried..................., but I'd like to.

(b) I'm very keen on.

(c) I would like to learn to

(d) I used to

given up now.

(e) Recently, I've taken up.

(f) I think to keep fit.

2b) Skeleton Dialogues

Work with a partner. You can complete the dialogue in any way you like.

A: Do you like learning English?

B: ......................... What about you?

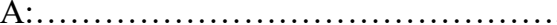

B: Have you been to an English-speaking country?

A: ................... What about you?

B: ....................................?

A: Which country would you most like to visit? $\mathrm{B}:$ and you?

2c) Informal interviews

a) What do you enjoy most about learning English?

b) What do you enjoy least about learning English?

c) What other language would you like to learn?

\subsection{Low Scaffolding Activities}

Low scaffolding activities still involve a degree of support for the learners. Learners are given a stimulus to speak and some guidance on interaction pattern, but they take a lot more responsibility for how the discussion develops.

3a) Semi-structured interviews

Here are some true statements about your teacher. Think of some questions you could ask your teacher to get more information e.g. When did you go to China?
(a) I have been to China.
(b) I like football.
(c) I went to university
(d) I can speak French, German and Italian.
(e) I am learning to play the drums 
3b) Pyramid Discussion

1. What are the most important qualities in a friend?

Put them in order of importance.

- Similar interests

- Similar personality

- A sense of humour

- Trust

- Generosity

2. Now compare your order with a partner.

3. Now for a group of 4 and see if you can agree an order.

3c) Structured Debates

1. Circle a number for each statement

$5=$ strongly agree $4=$ agree $3=$ not sure $4=$ disagree

$5=$ strongly disagree

(a) It is important to speak English in class.
54
4

$$
3
$$$$
21
$$

(b) I feel shy when I speak English in class.

$\begin{array}{lcccc}5 & 4 & 3 & 2 & 1 \\ \text { (c) } & \text { I like the teacher to speak } & \text { English in class. } \\ 5 & 4 & 3 & 2 & 1\end{array}$

\section{CONCLUSION}

I have spoken above in general terms about the need to carefully adjust the level of challenge as we move from high to low scaffolding activities. The level can be adjusted across four dimensions: linguistic; cognitive; psycholinguistic and affective. The linguistic level can be adjusted by providing, over time, activities which gradually require a wider range of lexis and more sophisticated grammar. We can adjust the cognitive level by gradually basing our activities on more complex and abstract topics. The psycholinguistic challenge can be adjusted by gradually allowing less preparation time and more spontaneity, while the affective challenge relates to the amount of personal or emotional involvement required. I would like to conclude with a summary of the general points I think we need to keep in mind when planning and carrying out speaking activities: 1) It makes a big difference to the quality of the output from speaking activities if learners are given specific points or specific questions to discuss rather than just a topic. It is also very helpful if the interaction is structured so that learners know when to respond and don't just wait for their partner to take the initiative.

2) Even a little mental planning and preparation time before the activity to gather ideas and perhaps some of the language needed for the activity can have a very positive effect on output.

3) Some speaking activities can be modelled by the teacher to give learners a clearer idea of what is required from them and to familiarise them with some of the language required.

4) It can be useful to pre-teach some language required for the activity. It is important, however, that this is restricted to a very limited amount of key language so that the learners are not overwhelmed. Practice and consolidation of this language is important before the learners are expected to use it in free practice.

5) It is important that teachers give feedback on the activity. This feedback should not just be correction, although a limited amount of selective correction can be used. It should also include feedback on good language the learners have produced and good ideas they have expressed.

6) As a round-up, depending on the nature of the activity, it can be interesting for the learners to ask the teacher some of the questions they have just discussed, or for the teacher to give his/her ideas on the topic.

7) Task repetition is an option that teachers should definitely consider. The learners, for example, can be asked to repeat the same activity with a different partner, or at a later date. Evidence shows that when they repeat an activity learners tend to use a wider range of vocabulary and grammar and tend to do it with more confidence.

\section{REFERENCES}

Burns, A. and Hill, D. (2013). Teaching speaking in a second language. In: Tomlinson, B. (ed.) Applied linguistics and materials development London: Bloomsbury, pp.231-251.

Goh, C. (2017) Research into practice: Scaffolding learning processes to improve speaking performance. Cambridge Language Teaching, 50/2, 247-260.

Hughes, R. (2010). Materials to develop the speaking skill. In: Harwood, N. (ed.) English language teaching textbooks: content, consumption, production (pp.207-224). Cambridge: CUP, pp.207-224.

Timmis, I. (2016) Humanising coursebook dialogues. Journal of Innovation in Language Learning and Teaching, 10/2, 144-153.

\section{FURTHER READING}

Bygate, M. (2001). Speaking. In: R. Carter and D. Nunan, The Cambridge Guide to TESOL. Cambridge: CUP, pp.14-20.

Dat, B. (2013). Materials for Developing Speaking Skills. In: Tomlinson, B. (ed.) Developing materials for language teaching. London: Bloomsbury, pp.231-251.

Mishan, F. and Timmis, I. (2015) Materials design for TESOL. Edinburgh: EUP.

Thornbury, S. (2005) How to teach speaking. Harlow: Pearson.

Timmis, I. (2016) Materials to develop speaking skills. In: Azarnoosh, M., Zeraatpishe, M., Faravani, A. and Kargozari, H. (eds.) Issues in materials development. Rotterdam: Sense, pp. 83-93. 


\section{APPENDIX}

\section{Coursebook Speaking Activity}

Read the restaurant reviews below then answer the following questions.

\section{Restaurant Reviews}

\section{Open 24 hours}

One of the most delicious chicken satays I've ever eaten. The meat was tender, the peanut sauce was really smooth and the rice cake was delicious. Perfect to eat for late night dinner.

\section{Sate Siboen}

It is one of the best sates I've ever eaten. Still tastes the same as the one I had years ago. Very tender chicken and sweet soya sauce makes it even better. Looking for the real sate? Visit this place when you are in town. They will not let you down.

\section{Satay Palace}

I used to go to this place and enjoy it. Their satay used to be tender, soft and, most importantly, grilled from fresh chicken. Now it's cooked, stored, then reheated on the grill before serving. It's hard and chewy, and that's just terrible.

What good qualities and negative qualities you found from the reviews?

Have you been to this place? If yes, which review do you agree most? And which do you disagree with? Give support to your opinion

What good qualities and negative qualities you found from the reviews?

Have you been to this place? If yes, which review do you agree most? And which do you disagree with? Give support to your opinion.

\section{Adapted Version}

\section{Let's talk about the food we like}

1. Read the 3 restaurant reviews below. Which review is negative and why?

\section{Restaurant Reviews}

\section{Open 24 hours}

One of the most delicious chicken satays I've ever eaten. The meat was tender, the peanut sauce was really smooth and the rice cake was delicious. Perfect to eat for late night dinner.

\section{Sate Siboen}

It is one of the best sates I've ever eaten. Still tastes the same as the one I had years ago. Very tender chicken and sweet soya sauce makes it even better. Looking for the real sate? Visit this place when you are in town. They will not let you down.

\section{Satay Palace}

I used to go to this place and enjoy it. Their satay used to be tender, soft and, most importantly, grilled from fresh chicken. Now it's cooked, stored, then reheated on the grill before serving. It's hard and chewy, and that's just terrible.

2. Underline the adjectives in the text above which describe food e.g. delicious.

3. Put the adjectives you have underlined into 3 groups:

a) Adjectives which describe meat

b) Adjectives which describe sauce

c) General adjectives to describe a meal

4. Mark the stress on the words you have underlined e.g. delicious.

5. Practise pronouncing the words with your teacher.

6. Complete this sentence:

One of the best .... I've ever eaten was at .... restaurant. We had ...

7. Read your sentence to your partner and tell him/her more about the meal and why you liked it.

8. Now listen to your teacher talk about the same topic. Ask him/her questions about the experience.

\section{Coursebook Activity}

Read the short comments below.

The biggest disadvantage for apartments is that, most of the time, they're smaller than houses. Houses usually include parking spaces or garages and, as you may know, finding a parking space in front of a crowded apartment complex can sometimes very difficult.

As far as security goes, apartments seem to be the better choice. Some apartment buildings have security guards and a lot of them feature secure front doors which can only be opened with a code or card. 
Work in pairs. Discuss other positive and negative things about living in a house and in an apartment.

\begin{tabular}{|l|l|}
\hline $\begin{array}{l}\text { Type of place } \\
\text { to live }\end{array}$ & Positive things \\
\hline A house & \\
\hline An apartment & \\
& \\
& \\
\end{tabular}

\section{Adapted Version}

1. Work in pairs. Make notes in the box about positive and negative things about living in a house and in an apartment. Here are some word which might help you:

Space; cheap; expensive; convenient; noisy [tip: the vowel in 'noisy' is the same as the vowel in 'boy']; quiet; private; small
2. Divide the words above into positive and negative categories and put them in box below.

3. Try to add your own words to each category

4. Practise pronouncing these words: expensive; convenient; noisy; private

\begin{tabular}{|l|l|l|}
\hline $\begin{array}{l}\text { Type of place } \\
\text { to live }\end{array}$ & $\begin{array}{l}\text { Positive } \\
\text { things }\end{array}$ & $\begin{array}{l}\text { Negative } \\
\text { things }\end{array}$ \\
\hline A house & & \\
\hline $\begin{array}{l}\text { An } \\
\text { apartment }\end{array}$ & & \\
& & \\
\end{tabular}

5. Now talk to your partner about what you would prefer and try to use some of the vocabulary from above:

I would prefer to live in a ....... because 
